\title{
Life history effects on hatchery contributions to ocean harvest and natural-area spawning
}

\begin{tabular}{|r|l|}
\hline Journal: & Canadian Journal of Fisheries and Aquatic Sciences \\
\hline Manuscript ID & cjfas-2016-0457.R1 \\
\hline Danuscript Type: & Article \\
\hline Complete List of Authors: & \begin{tabular}{rl|} 
Davison, Raziel; University of California Santa Cruz, Center for Stock \\
Assessment Research and Department of Applied Mathematics and \\
Statistics; Affiliated with Southwest Fisheries Science Center, Fisheries \\
Ecology Division, National Marine Fisheries Service, National Oceanic and \\
Atmospheric Administration \\
Satterthwaite, William; National Marine Fisheries Service, NOAA, Fisheries \\
Ecology Division, Southwest Fisheries Science Center; University of \\
California Santa Cruz, Center for Stock Assessment Research and \\
Department of Applied Mathematics and Statistics
\end{tabular} \\
\hline Keyword: & $\begin{array}{l}\text { hatchery, stray, LIFE HISTORY < General, MATURATION < General, } \\
\text { supplementation }\end{array}$ \\
\hline &
\end{tabular}


1

\section{Life history effects on hatchery contributions to ocean harvest and natural-area spawning}

Raziel J. Davison and William H. Satterthwaite

RAZIEL J. DAVISON ${ }^{1}$

Center for Stock Assessment Research, Department of Applied Mathematics and Statistics,

University of California, Santa Cruz, CA 95064

Affiliated with Southwest Fisheries Science Center, Fisheries Ecology Division, National Marine Fisheries Service, National Oceanic and Atmospheric Administration, 110 Shaffer Rd, Santa Cruz, CA 95060.

E-mail: raziel.davison@gmail.com

\section{WILLIAM H. SATTERTHWAITE*}

Fisheries Ecology Division, Southwest Fisheries Science Center, Fisheries Ecology Division, National Marine Fisheries Service, National Oceanic and Atmospheric Administration, 110 Shaffer Rd, Santa Cruz, CA 95060.

E-mail: Will.Satterthwaite@noaa.gov, Phone +1 (831) 420-3977, Fax +1 (831) 420-3977

\section{*Corresponding author}

\footnotetext{
${ }^{1}$ Present address: Department of Anthropology, Institute for Social, Behavioral and Economic Research, University of California Santa Barbara, Santa Barbara, CA 93106-2150, USA
} 


\section{Abstract}

18 Hatcheries can support salmon fisheries but also impact natural populations. We model the

19 proportional hatchery contributions to ocean catch, natural-area spawning and egg production

20 based on hatchery production, maturation, fecundity and straying. We develop indices of

21 hatchery-origin catch per stray spawner measuring the trade-off between supplementing

22 harvest and limiting natural-area impacts; higher values indicate success in increasing hatchery

23 ocean harvest contributions relative to strays spawning in natural areas. Hatchery fish maturing

24 early lowers catch per stray (and proportion hatchery-origin catch) by shifting the age

25 distributions of both catch and spawners toward younger ages. Age-dependent fecundity may

26 complicate predicted effects of changing maturation schedules. Increased straying does not

27 affect catch but increases hatchery-origin spawning and decreases catch per stray. Differences

28 in hatchery production affect hatchery contributions to both catch and spawning, exacerbating

29 the tradeoff between these conflicting goals but with no net effect on catch per stray. Fishery

30 intensity magnifies the effects of accelerated hatchery fish maturation by reducing spawning

31 contributions of older fish, with contrasting effects depending on whether hatchery fish mature

32 early versus late. 


\section{Introduction}

Given current freshwater habitat conditions in much of their range, an economically viable Pacific salmon (Oncorhynchus spp.) fishery likely depends on supplementation via hatchery production (Brannon 2004) but the net effect of hatcheries coastwide is difficult to ascertain (e.g., Hilborn et al. 1998; Ruckelshaus 2002; Morita et al. 2006) due to the complex interactions between hatchery and wild fish (Waples 1999; Naish et al. 2008). In addition, serious concerns have been raised about the effects that hatchery-origin fish have on naturallyspawning populations through competition for limited resources (e.g., Hilborn \& Hare 1992;

Kostow et al. 2003) and genetic introgression (e.g., Waples 1991; Utter 1998; Araki et al. 2008). Therefore, large production hatcheries are generally managed for multiple, sometimes conflicting goals: to boost overall fish production, and thus fishery harvest opportunity, while also controlling the impacts of straying fish on natural-area spawners and wild fish population dynamics. Ideally, hatchery-origin fish from large production hatcheries would make a large contribution to harvest and a small contribution to natural-area spawning, although hatchery fish spawning in natural areas adjacent to hatcheries are compatible with the goals of "integrated" hatchery programs (HSRG 2009). hatcheries release more fish, or when fish are released in a way that increases survival from the juvenile phase until recruitment to the fishery. Therefore, all else being equal, harvest opportunity is increased by hatchery practices that increase juvenile survival (Johnson et al. 1990; Solazzi et al. 1991; Satterthwaite et al. 2014a) and/or the rate at which hatchery fish grow to harvestable size. Although the effects of life history schedules may be less immediately 
55 obvious than the size and survival of hatchery releases, maturation rates of hatchery-origin fish also affect the degree to which they increase ocean harvest opportunity, since later-maturing fish experience more cumulative exposure to the fishery before returning to spawn (Hankin and Healey 1986). For example, the proportion of Chinook salmon (O. tshawytscha) catch in Lake Michigan made up by natural-origin fish was found to increase with age due to earlier maturation of hatchery fish (Williams 2012). If this pattern holds in the ocean as well, that would reduce hatchery contributions to ocean harvest, but potentially increase hatchery contributions to instream harvest as well as natural-area spawning, since more hatchery-origin fish would escape ocean harvest.

Similarly, the most obvious drivers of the impact of hatchery-origin fish on natural area spawning grounds are the number of juveniles released and their survival as well as the stray rates of adult fish returning to spawn. There is also concern about loss of local adaptation due to introgression from hatcheries (e.g. Hard et al. 1992; Quinn 1993), and such impacts are of course higher when hatchery and natural populations are less similar. The impact of straying depends on the proportion of natural-area spawners that originated in hatcheries (Naish et al. 2008), which depends not just on the proportion of hatchery production straying but also on the magnitude of hatchery production. Thus, low stray rates from very large hatcheries can have a larger impact than high stray rates from small hatcheries (Grant 1997). In addition, offsite releases increase juvenile survival (Johnson et al. 1990; Solazzi et al. 2011) but may also increase stray rates (e.g., Vreeland et al. 1975; Johnson et al. 1990; Lasko et al. 2014), amplifying the resultant impacts of hatchery-origin fish on natural area spawning. As with contributions to harvest, life history schedules may also have important, if less widely 
77 appreciated, effects on the impacts of hatchery-origin fish on natural spawning areas. As noted

previously, earlier maturation of hatchery fish could increase the proportion of hatchery-origin fish escaping the ocean fishery and potentially returning to natural spawning areas.

There are documented life history differences between hatchery and natural-origin fish, including size, and age distributions (e.g., Swain et al. 1991; Knudsen et al. 2006; Vainikka et al. 2010), reproductive traits (e.g. Fleming \& Gross 1993; Quinn 1993), survival and growth (e.g. Jonsson et al. 2003), see Naish et al. (2008) for a review of hatchery life history effects). Many studies track hatchery-origin proportions in fisheries harvest (e.g., Zaugg et al. 1983; Hilborn and Eggers 2000; Barnett-Johnson et al. 2007) and among natural-area spawners (e.g., Seelbach \& Whelan 1998; Kostow et al. 2003; Nickelson 2003). Stray rates vary widely among natural and hatchery populations (Quinn 1993) and straying of hatchery fish has been implicated in wild salmon declines (e.g., Hilborn and Eggers 2000), but much remains to be learned about the interactive effects of hatchery practices and their relative influences on total production, on the proportions of hatchery-origin fish in ocean and instream harvests, and on the contribution of hatchery-origin fish to natural-area reproduction.

\section{To better understand the integrated effects of hatchery practices on harvest} opportunity and natural area impacts, we developed a series of population models integrating the effects of hatchery production, survival, maturation and fecundity schedules, ocean harvest rates, and stray rates. We used these models to explore how life-history differences across the life cycle influence harvest opportunity and natural-area population dynamics through hatchery contributions to natural-area spawning, both in terms of spawning adults competing for redd sites and mating access, and in terms of hatchery contributions to eggs laid in natural areas. 
99 Hatchery contributions to natural-area spawning depend on production, survivorship,

100

101

102

103

104

105

106

107

108

109 maturation schedules, and straying, whereas contributions to birth cohorts also depend on fecundity. We are particularly interested in effects of maturation schedules because hatchery practices can alter maturation schedules (e.g., Knudsen et al. 2006; Hankin et al. 2009; Vainikka et al. 2010) and changes in maturation rates feed through age- and size-dependent differences in survival and reproductive success (e.g., Healey \& Heard 1983; Kaufman et al. 2009). Since early-maturing fish are more likely to survive to spawn but are often smaller and less fecund at maturity, we are interested in how hatchery differences in life history traits like survival, maturation, and fecundity trade off against one another, and interact with the intensity of ocean fisheries, to amplify or to dampen hatchery contributions to both ocean fishery catch and spawning in natural areas.

We use six metrics to interpret hatchery effects under scenarios in which hatchery life histories differ from wild populations in production and survival, maturation rates, fecundity and stray rates. We predict how each of these life history differences would affect: 1 . the proportion hatchery-origin among natural-area spawners (pHOS), 2. the proportion hatchery-origin among natural-area eggs produced $(p H O G), 3$. the proportion hatchery origin among ocean-harvested fish $(p H O C), 4$. the proportion of surviving hatchery-origin fish that end up in ocean harvest rather than returning to spawn $(p C), 5$. the proportion of hatchery-origin fish that end up spawning in natural areas rather than ocean harvest or returning to the hatchery $(p S)$, and 6 . the ratio between number of hatchery-origin fish caught in the ocean harvest and the number spawning in natural areas (CPS).

The first three metrics describe system-wide effects of hatchery fish on a system containing both hatchery and natural-origin fish (and so are sensitive to the size of hatchery programs relative to

https://mc06.manuscriptcentral.com/cjfas-pubs 
121 natural production), while last three metrics compare the per-capita fates of hatchery fish (and so do

122 not depend on relative population sizes). CPS directly captures the tradeoff, at an individual-hatchery

123 level, between contributing to ocean harvest versus contributing to strays spawning in natural areas. All

124 acronyms are defined in Table 1.

125 Methods

Population model

We developed a model of a hypothetical fall run Chinook salmon stock with both

128 natural-origin (denoted by a subscript $w$ when needed) and hatchery-origin (subscript $h$ )

129 components (see Table 1 for a complete list of variable definitions). We assume a discrete

130 sequence of events each year: maturing spawners from each cohort (age $a$ ) leave the ocean in

131 the fall (with age-specific maturation probabilities $b_{a}$ ), followed by a period of overwinter

132 survival (with probability $p_{\mathrm{a}}$ of surviving from age $a$ to age $a+1$ ) followed by a pulse of ocean

133 harvest (with age-specific fishing mortality $f_{a}$ ), cycling back to another opportunity for maturing

134 spawners to leave the ocean (see Fig. 1).

Following management convention for California stocks (O'Farrell et al. 2010), we

136 advance ocean fish by one age class after spawners return each fall, with the assigned ocean

137 age corresponding to the age ocean-caught fish would be assigned if they had instead spawned

138 at their next opportunity. We do not model an instream fishery, but we do separately track the

139 fraction of hatchery-origin fish which stray to natural areas with probability $y$, which we assume

140 is independent of age. Ocean fishing mortality $\left(f_{a}\right)$ is the product of a fully-vulnerable

141 exploitation rate ( $e$, the intensity of the fishery, roughly corresponding to fishing effort) and 
142 age-specific vulnerability $q_{a}$, yielding $f_{a}=e q_{a}$, with the oldest ages assumed to be fully

143 vulnerable $\left(q_{4}=q_{5}=1.0\right)$ and assuming no exposure to the fishery prior to age $2\left(q_{1}=0\right)$.

144 Given an initial cohort size of $N_{1}$ (corresponding to the number of juveniles released

145 from the hatchery or resulting from natural area production, we note that this lifestage may not

146 be referred to as age 1 in other studies), juvenile survival $p_{1}$ from release/ocean entry until the

147 start of ocean age 2, annual overwinter survival $p_{a}$ (from ages $a=2$ to the start of each next age

$148 a+1)$, and age-specific maturation probabilities $\left(b_{a}\right)$ and ocean fishery mortality $\left(f_{a}\right)$, we

149 calculate the preseason ocean abundance $\left(N_{a}\right)$ at each age:

150

(1) $\quad N_{a}=p_{a-1}\left(1-b_{a-1}\right)\left(1-f_{a-1}\right) N_{a-1}$.

We also calculate the ocean catch $\left(C_{a}\right)$ of age $a$ fish, as well as the number of fish

152 returning to spawn in freshwater $\left(R_{a}\right)$ at each age by applying the age-specific maturation rate

$153\left(b_{a}\right)$ to the fraction $\left(1-f_{a-1}\right)$ not removed by the fishery:

$154 \quad(2) \quad C_{a}=f_{a} N_{a}$;

155

(3) $R_{a}=b_{a}\left(1-f_{a}\right) N_{a}$.

We calculate all of the above for hatchery-origin and for natural-origin fish separately. In

157 addition, for hatchery-origin fish, we calculate the number of hatchery strays $(S)$ to natural

158 areas as the product of hatchery returns $(R)$ and hatchery stray rate $(y)$ :

159

(4) $\quad S_{a, h}=R_{a, h} y ; S_{T, h}=\sum_{a=2}^{5} R_{a, h} y$. 
162 natural areas ( $R_{a, w}$ for natural-origin fish and $S_{a, h}$ for hatchery-origin fish) and their age-specific 163 fecundities $\left(g_{a}\right)$ :

$164 \quad(5) \quad G_{a, w}=R_{a, w} g_{a, w}$;

165

(6) $\quad G_{a, h}=S_{a, h} g_{a, h}$.

Because salmon population dynamics are highly variable and to allow use of cohort ratio

167 as a model input rather than a dynamic model output, we do not run the model for multiple

168 generations or until it reaches an equilibrium solution. Rather, we project the short-term,

169 deterministic dynamics of a single cohort. If juvenile production $\left(N_{1}\right)$, vital rates $\left(p_{a}, b_{a}, g_{a}\right)$,

170 fishing intensity $(e)$ and stray rates $(y)$ are constant across years, the sum across cohorts within

171 a year is equal to the sum across ages within a cohort's lifecycle. Therefore we define the

172 subscript $T$ to indicate the sum across all ages 2 to $A$, where $A$ is the maximum achievable age

173 (assumed to have $b_{A}=1.0$, rendering $p_{A}$ irrelevant but we set $p_{A}=0$ to emphasize that this is the

174 terminal age class). Our model does not separate fish by sex and so it implicitly assumes a 50:50

175 sex ratio, that maturation schedules and fishery exposure are the same for both sexes, and $g_{a}$ is

176 discounted to one half the egg production of a female fish (equivalent to the production of

177 female eggs, assuming a 50:50 sex ratio). Alternatively, the model could be applied to each sex

178 separately, with $g_{a}$ reformulated to represent male mating success.

\section{Baseline parameterization}

Our model is intended to reflect a realistic set of vital rates for a Chinook salmon

181 population but not provide quantitative advice for any specific system. However, to establish

182 plausible values and ranges for parameters, we loosely based most of our parameterization on 
data from Klamath River Fall Chinook (KRFC), a hatchery-supplemented stock harvested subject to ocean harvest off the coasts of northern California and southern Oregon (PFMC 2016). We initially set all parameters equal between hatchery and natural-origin populations, with maximum age $A=5$ and set $N_{0}=1.0$ as an arbitrary scaling constant. Based loosely on natural mortality and maturation rate estimates for Iron Gate Hatchery fall run fingerling releases (Hankin and Logan 2010), we set survival probabilities $p_{1}=0.01, p_{2}=0.5$, and $p_{3}=p_{4}=0.8$, along with maturation probabilities $b_{2}=0.03, b_{3}=0.5, b_{4}=0.9$, and $b_{5}=1.0$. We assumed that ocean age 4 and age 5 fish were fully vulnerable to the fishery (vulnerability $q_{4}=q_{5}=1.0$ ) and set $q_{3}=$ 0.5 based on the approximate ratio between age- 3 and age- 4 exploitation rates calculated by Hankin and Logan (2010). We set $q_{2}=0.05$ based on the knowledge that ocean age 2 fish from some stocks are caught in recreational ocean fisheries (Satterthwaite et al. 2013), while setting $q_{1}=0$. We set fishing intensity $e=0.5$, approximately midway between the limit for age- 4 KRFC of 0.16 (strongly constrained by the co-occurring threatened California Coastal Chinook stock, O'Farrell et al. 2012a) and the Pacific Fishery Management Council's default fishing mortality rate corresponding to maximum yield $\left(F_{M S Y}\right)$ for Chinook salmon, 0.78 (Pacific Fishery Management Council 2016). The baseline value of $e=0.5$ appears roughly consistent with the average fraction of adults removed from Sacramento River Fall Chinook (O'Farrell et al. 2012b), a hatchery-supplemented stock that is heavily targeted by fisheries that are usually constrained by co-occurring stocks. For comparative purposes, we assume no straying of natural-origin fish and specify stray rate $y=0.3$ for hatchery-origin fish. Stray rates reported in the literature vary widely (e.g., Pascual et al. 1995; Westley et al. 2013), as does the very definition of a stray when it involves natural areas near the source hatchery (e.g., Keefer and Caudill 2012; Kormos et al. 
205 2012), but we picked this value for use in displaying the effects of changes in other parameters 206 when $y$ is held constant because it is well within the range reported for hatchery releases

207 (Pascual et al. 1995). Baseline age-specific fecundity was modeled after Mokelumne River fall208 run Chinook salmon from California's Central Valley (Kaufman et al. 2009).

\section{Perturbation analyses}

To understand the impacts of variation in life history parameters potentially affected by hatchery practices, we varied parameters individually with respect to the baseline and also explored interactive effects of sets of variables which analysis of our metrics (below) showed could mediate a tradeoff between the conflicting hatchery goals of supplementing harvest while avoiding strays spawning in natural areas. We held natural-origin parameters constant in

215 all projections. We varied stray rate $(y)$ over the range 0.01 to 0.90 to encompass the wide 216 range of values reported in the literature (e.g., Pascual et al. 1995; Westley et al. 2013) and 217 varied the fully vulnerable fishing mortality $(e)$ from 0.1 to 0.8 based loosely on O'Farrell et al.

218 (2012a) and PFMC (2016), respectively, as described in deriving the baseline $e$. applying a range of multipliers denoted by $\phi_{x}$, with the subscript $x$ representing the parameter

221 being multiplied. Because initial cohort size $\left(N_{1}\right)$ and juvenile survival $\left(p_{1}\right)$ only appear in our

222 model as a product, we varied their joint outcome $N_{2}$ by applying a cohort ratio $\left(\phi_{N}=N_{2, h}: N_{2, w}\right)$

223 varying from 0.1 to 8 to allow for a range of scenarios between a small hatchery program in 224 conjunction with a small stock to a hatchery-dominated system where over $90 \%$ of fish are of 225 hatchery origin (e.g., Barnett-Johnson et al. 2007). We assumed that the maturation multiplier 
$226 \phi_{b}$ applied equally to all ages, with the exception that no value of $b_{a}$ could exceed 1.0 (since

227 maturation rates cannot exceed $100 \%)$ and $b_{5}$ was fixed at $1.0\left(b_{x, h}=\min \left\{b_{x, w}, 1\right\}\right)$. We set a

228 lower bound of 0.1 on $\phi_{b}$ loosely based on the reported minimum age-3 maturation rates for

229 Cole Rivers Hatchery (on the nearby Rogue River) spring run Chinook of 0.06 (Hankin and Logan

2302010 ) and an upper bound of 8.0 was loosely based the reported maximum age-2 maturation

231 rate of 0.16 for Sacramento River Winter Chinook (O'Farrell et al. 2012b). Of particular

232 relevance, $\phi_{b}=2.0$ yields an age- 3 maturation rate of $100 \%$ while $\phi_{b}=0.5$ roughly corresponds

233 to the approximate ratio between mean age-3 maturation rates estimated for Iron Gate

234 Hatchery fall fingerling (0.48) versus yearling (0.24) releases (Hankin and Logan 2010).

We also examined the effects of fecundity differences between hatchery and natural-

origin fish. Because selection for large egg size is relaxed in hatchery fish, fecundity selection

237 may favor large broods of small eggs (Heath et al. 2003; Fleming et al. 2003). However,

238 fecundity has declined significantly at some hatcheries (e.g., Williams 2006), and obtaining

239 accurate estimates of fecundity is difficult and empirical estimates must be interpreted with

240 caution (Beacham et al. 2003; Fleming et al. 2003; Beacham 2010). We model hatchery fish

241 fecundity by applying the scalar multiplier $\left(\phi_{g}=g_{x, h}: g_{x, w}\right.$ ranging from 0.1 to 8 , hereafter

242 'fecundity ratios') to baseline age-specific fecundity rates $\left(g_{a}\right)$ just as we did for maturation

243 probabilities $\left(b_{a}\right)$, with the exception that there is no upper bound on hatchery fecundity.

244 Metrics

Our model allows straightforward prediction of commonly measured quantities such as

246 the proportion hatchery-origin spawners (strays) in natural areas ( $p H O S)$, which depends on the 
247 number of strays $\left(S_{T, h}\right)$ and returning natural-origin fish $\left(R_{T, w}\right)$; the proportion hatchery-origin 248 among eggs laid in natural areas ( $p H O G)$, which depends on egg production of hatchery-origin

249 fish $\left(G_{T, h}\right)$ and natural-origin fish $\left(G_{T, w}\right)$; and the proportion hatchery-origin fish in the ocean 250 catch $(p H O C)$, which depends on total catch of hatchery- $\left(C_{T, h}\right)$ and natural-origin fish $\left(C_{T, w}\right)$ :

251

(7) $\quad$ HOS $=\frac{S_{T, h}}{R_{T, w}+S_{T, h}}$,

252

(8) $\quad$ pHOG $=\frac{G_{T, h}}{G_{T, w}+G_{T, h}}$, and

253

(9) $\quad$ PHOC $=\frac{C_{T, h}}{C_{T, h}+C_{T, w}}$.

While these metrics are commonly measured in the field, so many parameters influence them that it can be difficult to gain general insights by looking at their responses to only one or two parameters at a time. We therefore developed additional metrics of hatchery performance that are independent of natural-origin numbers, and thus provide scale-independent information on how hatchery practices influence the tradeoff between supplementing harvest and impacting natural area spawning. Whereas we used $p H O C$ to estimate hatchery-origin

260 proportions in ocean harvest, we calculate the proportion of surviving hatchery production (i.e., 261 not lost to natural mortality except through spawning) contributing to the ocean catch $(p C)$ to 262 predict the likely distribution of outcomes for hatchery fish:

$263 \quad(10) \quad p C=\frac{C_{T, h}}{R_{T, h}+C_{T, h}}$.

264 Note that $p C$ describes the chance of a hatchery fish being caught (a trait of hatchery fish in 265 particular) while $p H O C$ describes the chance of finding a hatchery fish among ocean harvest (a 
266 trait of the mixed fishery). Likewise, in addition to the proportion hatchery-origin fish in natural-

267 area spawning ( $p H O S)$ we also calculate the proportion of hatchery fish ending up as strays

268 spawning in natural areas $(p S)$ as:

$269 \quad$ (11) $\quad p S=\frac{S_{T, h}}{R_{T, h}+C_{T, h}}$.

270 Note that because hatchery-origin fish returning to the hatchery $\left(R_{T, h}-S_{T, h}\right)$ are not included in

271 the numerator of either $p C$ or $p S$, these two metrics do not sum to 1.0 unless the stray rate $y=$

2721.0.

273

The tradeoff between harvest contribution and straying is reflected in the ratio of

274 hatchery-origin ocean catch per stray spawner (CPS):

$275 \quad(12) \quad C P S=\frac{C_{T, h}}{S_{T, h}}$.

276

If CPS is high then it is likely that an individual hatchery fish will be caught in the ocean

277 harvest instead of spawning in natural areas, reflecting success in balancing the dual goals of

278 contributing to ocean harvest while avoiding impacts associated with strays spawning in

279 natural-areas.

280

Note that none of these metrics explicitly account for fish dying of natural mortality in

281 the ocean (or during downstream migration of juveniles). Metrics accounting for fish "lost" to

282 natural mortality might be of interest in future studies examining the ecosystem role of

283 hatchery salmon as food sources for predators. 


\section{Results}

286 Individual rate effects

Higher cohort ratios (i.e., the ratio of hatchery- to natural-origin cohort size, $\phi_{N}$ ) increase

the proportion hatchery-origin fish among natural area spawners ( $p H O S$ ) and among ocean

catch $(p H O C)$, but do not alter the proportion of hatchery fish ending up in ocean catch $(p C)$ or

spawning in the wild $(p S)$ because both of these measures are standardized to the size of

hatchery cohorts (see Fig. $2 a$ ). Maturation ratios $\left(\phi_{b}\right)$ affect all four metrics ( $p H O S, p H O C, p C$,

$p S)$ but there are diminishing returns to increasing maturation ratios beyond $\phi_{b}{ }^{*}$, the critical

threshold where all fish mature by age $3\left(\phi_{b}{ }^{*}=2.0\right.$ in this case, see Fig. $\left.2 b\right)$. Earlier maturation

(higher $\phi_{b}$ ) decreases $p H O C$ and $p C$ as more hatchery fish leave the ocean earlier and are

therefore exposed to less fishing hazard, but earlier maturation increases $p H O S$ and $p S$ since

early-maturing hatchery fish are more likely to survive and contribute to natural-area spawning

297 (see Fig. 2b). Higher fishing intensity $(e)$ increases $p C$ and reduces $p S$ as more hatchery fish are

298 caught before they return to spawn, but the proportion hatchery-origin among spawners

$299(p H O S)$ and ocean catch $(p H O C)$ are unaltered because fishing intensity affects hatchery and

natural-origin fish equally (see Fig. $2 c$ ). Higher stray rates $(y)$ directly increase the proportion of

hatchery-origin fish that end up spawning in natural areas $(p S)$ and the proportion of natural

area spawners that are of hatchery origin (pHOS, see Fig. $2 d$ ). If hatchery cohorts are equal in 
Hatchery contributions to natural-area spawning

The proportion of hatchery-origin strays among natural-area spawners ( $p H O S$ ) increases with higher stray rates ( $y$, Fig. $3 a, d, e)$, higher maturation ratios $\left(\phi_{b}\right.$, Fig. $\left.3 a, b, c\right)$, and higher cohort ratios $\left(\phi_{N}\right.$, Fig. $\left.3 c, d, f\right)$, but pHOS does not respond to fishing intensity $(e)$ when hatchery fish mature at the same ages as natural-origin fish (Fig. $3 e, f)$. When hatchery fish mature before natural-origin fish $\left(\phi_{b}<1\right)$, increasing fishing intensity $(e)$ reduces pHOS but if hatchery fish mature late $\left(\phi_{b}>1\right)$ then increasing fishing intensity increases $p H O S$ (see Fig. $3 b$ ). pHOS responds more to increasing stray rates when stray rates are initially low (Fig. 3a, $d, e)$ but responds more to higher cohort ratios when cohort ratios are large (Fig. $3 c, d, f$ ). pHOS responds less to higher maturation ratios $\left(\phi_{b}\right)$ when hatchery fish mature very late or very early, and respond much less to earlier maturity when maturation ratios are above the critical maturation threshold $\left(\phi_{b}{ }^{*}=2.0\right.$ in this parameterization) where all hatchery fish mature by age 3.

\section{Hatchery contributions to natural-area egg production}

Higher fecundity ratios (i.e., the ratio of hatchery-origin to natural origin fecundity, $\phi_{g}$ ) increase the proportion of natural-area egg production derived from hatchery-origin fish $(p H O G)$ but do not alter the age structure of spawners. Higher fecundity ratios $\left(\phi_{g}\right)$ act in conjunction with higher stray rates (y) to increase $p H O G$ (Fig. $4 a$ ) in exactly the same manner they interact with hatchery cohort ratios $\left(\phi_{N}\right.$, Fig. $\left.4 b\right)$. The two scalar multipliers $\phi_{g}$ and $\phi_{N}$ compound their effects on pHOG (Fig. 4c). Like spawner proportions ( $p H O S$, Fig. 3), egg proportions $(p H O G)$ respond more to increasing maturation ratios $\left(\phi_{b}\right)$ when maturity is late 
327 (low $\phi_{b}$, Fig. $4 d-g$ ) and respond more to increasing cohort ratios $\left(\phi_{N}\right)$ when hatchery cohorts are 328 large (high $\phi_{N}$, Fig. $4 b, c$, and $e$ ), and $p H O G$ responds identically to changes in cohort ratios $\left(\phi_{N}\right)$ 329 or fecundity ratios ( $\phi_{g}$, compare Fig. $4 e$ and $f$ ). Also like spawner proportions, egg proportions 330 show little response to increasing maturity ratios $\left(\phi_{b}\right)$ beyond $\phi_{b}{ }^{*}$ (Fig. $4 d-g$ ). Higher fishing 331 intensity $(e)$ increases pHOG when hatchery fish mature late $\left(\phi_{b}<1\right)$ and higher fishing intensity 332 decreases pHOG when hatchery fish mature early $\left(\phi_{b}>1\right.$, Fig. $\left.4 g\right)$.

Hatchery contributions to ocean harvest

The proportion of ocean catch comprising hatchery-origin fish $(p H O C)$ goes up with 335 larger cohort ratios $\left(\phi_{N}\right)$, with the largest effect from a given change in cohort ratios occurring 336 when hatchery and natural-origin cohorts have similar initial abundance $\left(\phi_{N} \approx 1\right.$, Fig. $\left.5 a, c\right)$.

337 Differences in maturation ratios also have the largest effect on $p H O C$ when hatchery- and 338 natural-origin fish mature at close to the same rates $\left(\phi_{b} \approx 1\right)$ and there is little effect of 339 increasing maturation ratios beyond the threshold $\phi_{b}$ (Fig. $5 b, c$ ). When hatchery fish mature 340 late $\left(\phi_{b}<1\right)$, increasing fishing intensity $(e)$ reduces the proportion hatchery-origin in ocean 341 catch $(p H O C)$ but when hatchery fish mature early $\left(\phi_{b}>1\right)$ increasing fishing intensity increases 342 pHOC (Fig. 5b). Catch per stray spawner (CPS) increases with fishing intensity $(e$, Fig. $5 d, e)$ and

344 decreases with both stray rate ( $y$, Fig. $5 d, f)$ and maturation ratios $\left(\phi_{b}\right.$, Fig. $\left.5 e, f\right)$, but does not 345 respond much to increases in maturation ratios beyond $\phi_{b}{ }^{*}$. 
347

\section{Discussion}

Our model indicates that hatchery contributions to ocean harvest (generally regarded as desirable) could be increased by larger numbers of hatchery fish released, by higher survival of hatchery releases, or by later maturation of hatchery fish, while proportional contributions of hatchery- versus natural-origin fish to ocean harvest are insensitive to stray rates. At the same time, hatchery contributions to natural area spawning (generally regarded as undesirable, at least for large production hatcheries) are decreased by smaller numbers of hatchery fish released, lower survival of hatchery fish, lower stray rates, or later maturation of hatchery fish. Thus the total size and survival of hatchery releases have opposite effects on the dual goals of maximizing hatchery contribution to harvest and minimizing straying of hatchery fish to natural spawning areas, while the remaining factors have some potential to at least partially mediate a tradeoff.

By exploring the effects of multiple parameters individually or in concert, we have explored the sensitivity of model results to most input parameters. Although we used only a single set of age-specific fishing vulnerability and age-specific fecundity, further simulations show that the modeled effects of changes in stray rates and maturation schedules on catch per stray egg are qualitatively robust and show minimal quantitative changes unless fecundity decreases strongly with age (see online supplement, Fig S1). Effects of straying and maturation rates on catch per stray spawner weaken but are not reversed if fishing vulnerability decreases with age (online supplement, Fig S2), since cumulative exposure to fisheries always increases with age. Neither of those scenarios is plausible. It is well established that fecundity in salmon increases with age (e.g., Mangel 1994) and the same is almost certainly true of fishing 
369 vulnerability. There may be small age-specific differences in ocean spatial distribution and thus 370 exposure to fisheries (Satterthwaite et al. 2013, 2014b), but for ages recruited to the fishery 371 these differences are small and fishing vulnerability primarily reflects the effects of minimum 372 size limits (Satterthwaite et al. 2012, McHugh et al. 2015), with older fish being larger and thus 373 more often legal to retain. Although a simplified theoretical model such as this one is difficult to fully validate with empirical data, we note that consistent with generally earlier maturation of hatchery-origin fish,

376 empirical studies have observed decreasing proportions hatchery-origin catch for older age 377 classes in Lake Michigan Chinook (Williams 2012). The spawning escapement of Central Valley 378 fall Chinook appears to have a higher proportion hatchery-origin than the ocean harvest off

379 Central California (Rachel Johnson, National Marine Fisheries Service, Santa Cruz, California, 380 personal communication, based on calculations performed using data reported in Kormos et al.

3812012 and Palmer-Zwahlen and Kormos 2013 and 2015), although natural-origin fish from 382 northern stocks may make small contributions to harvest off Central California (Bellinger et al. 383 2015; Satterthwaite et al. 2015). Future work could investigate the effects of stronger or 384 weaker differences in the fecundity of young vs. old fish, variation in how rapidly fishery 385 vulnerability increases with age, density-dependence, or stochastic effects. releases or increased juvenile survival) increase both the number of hatchery fish harvested and the number of hatchery fish escaping to natural spawning areas, exacerbating the tradeoff 
390 between the dual management goals of increasing hatchery harvest contributions but reducing 391 hatchery inputs to natural-area spawning. Thus, hatchery cohort size has no potential to 392 mediate between these opposing goals but scales the magnitude of this tradeoff. This is made 393 readily apparent by comparisons of different metrics - the proportion hatchery-origin among ocean catch $(p H O C)$ and among natural area-spawners $(p H O S)$ show opposite responses to hatchery cohort size, whereas measures of individual fish fates ( $p S$ and $p C$, the proportion 396 straying or caught) and metrics of hatchery performance that are independent of the relative 397 sizes of hatchery and natural populations such as catch per stray spawner (CPS) show no 398 response. It seems important to note here that empirical measures of $p H O C$ (e.g., Barnett399 Johnson et al. 2007; Kormos et al. 2012) and pHOS (e.g., Johnson et al. 2012; Kormos et al. 400 2012; Hinrichsen et al. 2016) are common in the literature, but we are not aware of estimates 401 of the latter quantities (i.e., $p S, p C, C P S$ ). This suggests that consideration of empirical measures 402 of the latter metrics may be helpful in informing hatchery managers on their success in trading 403 off between competing goals, given the overall size of the hatchery program.

Stray rate

Lowering stray rates would reduce impacts of straying spawners without altering ocean

406 harvest in terms of either numbers or composition and thus, in isolation, reductions in stray 407 rates present no conflict for the dual goals of fisheries supplementation and natural-area 408 conservation. However, hatchery fish are often released offsite to increase their survival and 409 thus increase their contribution to ocean fisheries (Johnson et al. 1990; Solazzi et al. 1991), but 410 such offsite releases may increase stray rates (Vreeland et al. 1975; Johnson et al. 1990; Lasko 411 et al. 2014). It is possible that the survival advantage might be lost if hatchery practices were 
412 altered to reduce straying, sacrificing harvest opportunity. In addition, onsite releases may lead

413 to increased instream competition with naturally-produced juveniles.

414 Fecundity

415 Similar to stray rates, reducing the fecundity of hatchery fish has no effect on

416 contributions to harvest but reduces the number of hatchery-origin juveniles present in the

417 next generation of natural-area fish and thus reduces the genetic impact of strays. Therefore

418 releasing hatchery fish with lower fecundity (or zero fecundity in the case of triploids) might

419 reduce the production of hatchery-origin juveniles in natural areas, and so reduce the

420 population genetic impacts of straying, but lower fecundity hatchery fish would still compete

421 for redd sites and mates and might introduce genes or gene combinations leading to low

422 fecundity into natural populations.

423 Maturation schedule

Our model suggests that alterations in hatchery maturation schedules could contribute

425 to achieving both goals of hatchery production by inducing delayed maturation, which would

426 both increase hatchery contributions to harvest and decrease hatchery impacts through natural

427 area spawning. Although delayed maturity of hatchery fish always reduces the contribution of

428 hatchery spawners to natural area spawning, the effects on egg production are harder to

429 predict and may be reversed, because older spawners have higher fecundity. The net effect of

430 changes in age structure on age production reflect a complicated tradeoff among multiple age

431 classes and so will depend on the specific mortality and fecundity schedule for a particular

432 system. In our particular parameterization, the increase in fecundity with greater age was not 
433 large enough to compensate for intervening mortality, so delayed maturation never increased

434 the proportional contribution of hatchery-origin eggs. However a different pattern might arise if 435 the increase in fecundity with age were stronger. In addition, larger fish tend to have larger 436 eggs (Kinnison et al. 2001) that are more likely to produce surviving offspring (e.g., Williams et 437 al. 2006; Heath et al. 1999), but this effect of delayed maturation is not accounted for in our 438 model. Because increased fishing intensity dampens the effects of changes in maturation 439 schedules on the composition of catch and returning spawners, higher fishing intensity may 440 reduce the observed impacts of early maturation in terms of spawner composition, but it may 441 reduce the observed benefits of delayed maturation in terms of harvest composition.

Although there is extensive literature on the effect of hatchery practices on maturation

443 schedules (e.g., Knudsen et al. 2006; Hankin et al. 2009; Vainikka et al. 2010), the potential for

444 changes in maturation schedules to contribute to achieving these management goals does not 445 seem to be widely appreciated (but see Hankin and Healy 1986 for hatchery contributions to 446 harvest). For example, despite extensive attention to the tension between supplementing 447 harvest and avoiding natural area impacts, the Hatchery Scientific Review Group (HSRG 2014) 448 did not discuss the effects of hatchery practices on maturation schedules. The California 449 Hatchery Scientific Review Group (California HSRG 2012) did discuss the effects of hatchery 450 practices on maturation schedules, and the implications of altered maturation schedules for 451 equivalence to natural populations in "integrated" hatchery programs, but they did not 452 consider maturation schedules with respect to the goals of supplementing harvest or limiting 453 stray spawners. 
In many cases, existing hatchery practices tend to favor earlier maturation (e.g.,

455 Knudsen et al. 2006; Hankin et al. 2009; Vainikka et al. 2010), conflicting with both harvest and

456 spawner goals, but this need not universally be the case. For example, since much of the

457 variation in age at maturity is heritable (Hankin et al. 1993), careful broodstock selection could

458 reverse the tendency toward early maturation in hatchery fish (California HSRG 2012).

459 Additionally, fall run Chinook salmon held for extended rearing periods and released the

460 following fall as "yearlings" tend to mature later than earlier releases (Hankin 1990). Among

461 wild salmon, however, size at ocean entry is negatively correlated with age at maturity (e.g.,

462 Vollestad et al. 2004), and so yearling releases (of larger fish) may not delay maturity in all

463 cases, although timing effects may predominate over the effects of size at release.

However, attempts to induce later maturation in hatchery fish would not be without

complications. Although random or haphazard broodstock selection likely leads to unnaturally

early maturation in hatchery salmon (Hankin et al. 2009), deliberately swinging the pendulum

467 too far in the opposite direction and selecting for later maturation than natural fish could pose

468 problems for "integrated" hatchery programs intended to match the life histories of natural-

469 origin fish (California HSRG 2012). Yearling releases may be exposed to increased domestication

470 selection due to their extended rearing in the hatchery and thus may introduce undesirable

471 traits if spawning in natural areas or used as broodstock upon their return (California HSRG

472 2012). In addition, later maturity may allow hatchery fish to grow larger, making them more

473 effective competitors for spawning sites and having higher fecundity. Yearling releases could

474 also increase the expense of hatchery operations due to their extended rearing, although due

475 to higher survival of yearling releases and their increased exposure to the fishery (Hankin 1990), 
476 this may be partially compensated by the smaller number of yearling fish needed to yield the

477 same fishery benefit as earlier releases. Also, because yearlings are released in the fall after

478 naturally-spawned juveniles have migrated to the ocean, this would likely decrease competition

479 for instream resources (California HSRG 2012).

This higher survival of yearling releases would also, if all else is held constant, partially

481 counter the benefit of later maturation in reducing hatchery impacts on natural area spawning due to increases in the total number of surviving hatchery fish. Additionally, there is a trade-off

483 between maturity and fecundity in which the lower fecundity of early-maturing fish reduces

484 hatchery contributions to natural-area egg production and the potentially lower offspring 485 survival from smaller eggs further reduces hatchery contributions to future generations (e.g.,

486 Kostow et al. 2003), whereas the higher fecundity and larger eggs of later-maturing hatchery

487 fish could increase their genetic impacts. Finally, there is some evidence that older fish are 488 more likely to stray (e.g., Quinn and Fresh 1984; Pascual et al. 1995), again potentially 489 countering some of the benefit of later maturation of hatchery fish for natural area spawning 490 impacts.

491 Synthesis

Taken together, our results suggest that consideration of life history can help mediate

493 between the conflicting hatchery goals of contributing to ocean harvest while reducing the 494 impacts of hatchery spawners straying into natural areas. The roles of hatchery size and stray 495 rates are already well appreciated (e.g., Grant 1997). It is also intuitively obvious that reduced 496 fecundity of hatchery fish will reduce their contribution to juvenile production in natural areas, 
497 although the competitive and genetic consequences of low-fecundity spawners intermingling

498 with natural-origin fish need to be carefully considered, especially in the context of "integrated

499 hatcheries". Our model also quantifies the effects of maturation schedule and its interaction

500 with fecundity effects, with delayed maturation increasing the contribution of hatchery fish to

501 the harvest and decreasing the impacts of stray spawners in natural areas. In contrast,

502 however, hatchery contributions to natural-area egg or juvenile production may sometimes

503 increase with later maturity because older spawners have higher fecundity or higher survival

504 from egg to fry. Thus, with the possible exception of egg/fry production, it appears hatcheries

505 can best meet their conflicting goals by working to reduce stray rates and not foster early

506 maturation. Which of these options is likely to provide greater returns is likely to be context-

507 dependent. If stray rates are high (e.g., $80 \%$ or higher in some cases, Pascual et al. 1995), there

508 is great scope to achieve benefits by reducing them, but if stray rates are minimal, reducing

509 them further would yield diminishing returns. At least in some cases, there may be substantial

510 scope for reducing early maturation rates (e.g., Hankin and Logan 2010 report as great as a 50\%

511 reduction in the age-3 maturation rate). Reducing the early maturation of hatchery fish may be

512 especially helpful when the ocean fishery exploitation rate is high, skewing the spawner age

513 composition toward younger fish. This suggests that steps to delay maturation in hatchery fish,

514 or at least avoid unnaturally early maturation, may be an important alternative to consider in

515 attempts to minimize hatchery impacts on natural areas while contributing to ocean harvest.

\section{Acknowledgments}

This manuscript was improved through discussions with David Boughton, Stephanie

518 Carlson, Rachel Johnson, Joe Merz, Michael Mohr, Steve Munch, and Michael O'Farrell; as well 
519 as by the comments of two anonymous reviewers. RJD was supported by California Department

520 of Fish and Game Ecosystem Restoration Program Grant Agreement E1183014. 


\section{References}

522 Araki, H., Cooper, B., and Blouin, M.S. 2008. Genetic effects of captive breeding cause a rapid, 523 cumulative fitness decline in the wild. Science, 318: 100-103.

524 Barnett-Johnson, R., Grimes, C.B., Royer, C.F., and Donohoe, C.J. 2007. Identifying the 525 contribution of wild and hatchery Chinook salmon (Oncorhynchus tshawytscha) to the ocean

526 fishery using otolith microstructure as natural tags. Can. J. Fish. Aquat. Sci. 64(12): 1683-1692.

527 Beacham, T.D. 2003. Comment on "Rapid Evolution of Egg Size in Captive Salmon" (II). Science, $528 \quad 302(5642):$ 59-59.

529 Beacham, T.D. 2010. Revisiting trends in the evolution of egg size in hatchery-enhanced 530 populations of Chinook salmon from British Columbia. T. Am. Fish. Soc. 139(2): 579-585.

531 Brannon, E. L., Amend, D.F., Cronin, M.A., Lannan, J.E., LaPatra, S., McNeil, W.J., Noble, R.E.,

532 Smith, C.E., Talbot, A.J., Wedemeyer, G.A., and Westers, H. 2004. The controversy about salmon 533 hatcheries. Fisheries, 29(9): 12-31.

534 California Hatchery Scientific Review Group (California HSRG). 2012. California Hatchery Review 535 Report. Prepared for the US Fish and Wildlife Service and Pacific States Marine Fisheries 536 Commission. Available from http://cahatcheryreview.com/reports/.

537 Fleming, I.A., and Gross, M.R. 1993. Breeding success of hatchery and wild coho salmon 538 (Oncorhynchus kisutch) in competition. Ecol. Appl. 3(2): 230-245.

539 Fleming, I.A., Einum, S., Jonsson, B. and Jonsson, N. 2003. Comment on "Rapid Evolution of Egg 540 Size in Captive Salmon" (I). Science, 302(5642): 59. 
541 Grant, W.S. 1997. Genetic effects of straying of non-native hatchery fish into natural

542 populations: proceedings of the workshop. NOAA Tech. Memo. NOAA-TM-NMFS-NWFSC-30.

543 Hankin, D.G. 1990. Effects of month of release of hatchery-reared Chinook salmon on size at

544 age, maturation schedule and fishery contribution. Oregon Dept. of Fish and Wildlife.

545 Information Report 90-4. Available from

546 http://docs.streamnetlibrary.org/Oregon/DFW/inforept90-4.pdf.

547 Hankin, D.G., and Healey, M.C. 1986. Dependence of exploitation rates for maximum yield and 548 stock collapse on age and sex structure of chinook salmon (Oncorhynchus tshawytscha) stocks.

549 Can. Fish. Aquat. Sci. 43(9): 7746-1759.

550 Hankin, D.G., and Logan, E. 2010. A preliminary analysis of Chinook salmon coded-wire tag

551 recovery data from Iron Gate, Trinity River and Cole Rivers Hatcheries, brood years 1978-2004.

552 Prepared for The Hoopa Valley Tribal Council and the Arcata Office, U.S. Fish and Wildlife

553 Service. Available from

554 https://www.fws.gov/arcata/fisheries/reports/technical/IGHTRH.CWTanalysis2009\%20Hankin\% $555 \quad$ 20Rpt.pdf

556 Hankin, D.G., Nicholas, J.W., and Downey, T.W. 1993. Evidence for inheritance of age of

557 maturity in chinook salmon (Oncorhynchus tshawytscha). Can. J. Fish. Aquat. Sci. 50(2): 347-

558358.

559 Hankin, D.G., Fitzgibbons, J., and Chen, Y. 2009. Unnatural random mating policies select for 560 younger age at maturity in hatchery Chinook salmon (Oncorhynchus tshawytscha) populations.

561 Can. J. Fish. Aquat. Sci. 66(9): 1505-1521. 
562 Hard, J.J., Jones Jr, R.P., Delarm, M.R. and Waples, R.S. 1992. Pacific salmon and artificial

563 propagation Under the Endangered Species Act. NOAA Tech. Memo. NMFS-NWFSC-2.

564 Healey, M.C., and Heard, W.R. 1984. Inter-and intra-population variation in the fecundity of

565 chinook salmon (Oncorhynchus tshawytscha) and its relevance to life history theory. Can. J.

566 Fish. Aquat. Sci. 41(3): 476-483.

567 Heath, D.D., Fox, C.W., and Heath, J.W. 1999. Maternal effects on offspring size: variation

568 through early development of Chinook salmon. Evolution, 53(5):1605-1611.

569 Heath, D.D., Heath, J.W., Bryden, C.A., Johnson, R.M., and Fox, C.W. 2003. Rapid evolution of 570 egg size in captive salmon. Science, 299(5613): 1738-1740.

571 Hilborn, R. 1998. The economic performance of marine stock enhancement projects. B. Mar.

572 Sci. B. Mar. Sci. 62(2): 661-674.

573 Hilborn, R., and Eggers, D. 2000. A review of the hatchery programs for pink salmon in Prince

574 William Sound and Kodiak Island, Alaska. T. Am. Fish. Soc. 129(2): 333-350.

575 Hilborn, R., and Hare, S.R. 1992. Hatchery and wild fish production of anadromous salmon in 576 the Columbia River basin. Fisheries Research Institute Tech. Rep. FRI-UW-9207. Available from

577 https://digital.lib.washington.edu/researchworks/bitstream/handle/1773/4173/9207.pdf?sequ 578 ence.

579 Hinrichsen, R.A., Steele, C.A., Ackerman, M.W., Campbell, M.R., Narum, S.R., Hess, M.A., Young, 580 W.P., Shields, B.A., Nez Perce Tribe, and Maschhoff, B.L. 2016. Maximum likelihood estimation 
581 of the proportion of hatchery-origin fish on spawning grounds using coded wire tagging and 582 parentage-based tagging. T. Am. Fish. Soc. 145(3): 671-686.

583 HSRG (Hatchery Scientific Review Group). 2009. Columbia River hatchery reform system-wide 584 report. Bonneville Power Administration and NOAA Fisheries. Available from 585 http://hatcheryreform.us/hrp/uploads/C1EKAOMVHURK/01_HSRG\%20Final\%20Systemwide\%2 586 OR eport.pdf.

587 HSRG (Hatchery Scientific Review Group). 2014. On the Science of Hatcheries: An updated 588 perspective on the role of hatcheries in salmon and steelhead management in the Pacific 589 Northwest. Available from

590 http://www.hatcheryreform.us/hrp/reports/hatcheries/welcome_show.action.

591 Johnson, R.C., Weber, P.K., Wikert, J.D., Workman, M.L., MacFarlane,R.B., Grove, M.J., and 592 Schmitt, A.K. 2012. Managed metapopulations: Do salmon hatchery 'sources' lead to in-river 593 'sinks' in conservation? PLOS ONE 7(2): e28880.

594 Johnson, S.L., Solazzi, M.F., and Nickelson, T.E. 1990. Effects on survival and homing of trucking 595 hatchery yearling coho salmon to release sites. N. Am. J. Fish. Manag. 10(4): 427-433.

596 Jonsson, N., Jonsson, B., and Hansen, L.P. 2003. The marine survival and growth of wild and 597 hatchery-reared Atlantic salmon. J. Appl. Ecol. 40(5): 900-911.

598 Kaufman, R.C., Houck, A.G., Workman, M., and Cech, J.J., Jr. 2009. Chinook salmon 599 length/fecundity: a regression model for the Mokelumne River, California. Calif. Fish Game, 600 95(2): 88-105. 
601 Keefer, M.L., and Caudill, C.C. 2012. A review of adult salmon and steelhead straying with an 602 emphasis on Columbia River populations. Technical Report 2012-6. Department of Fish and 603 Wildlife Resources, College of Natural Resources, University of Idaho. Available from 604 http://www.dfw.state.or.us/fish/OHRC/docs/2013/pubs/steelhead_and_salmon_straying.pdf.

605 Kinnison, M.T., Unwin, M.J., Hendry, A.P., and Quinn, T.P. 2001. Migratory costs and the 606 evolution of egg size and number in introduced and indigenous salmon populations. Evolution, $607 \quad 55(8): 1656-1667$.

608 Knudsen, C.M., Schroder, S.L., Busack, C.A., Johnston, M.V., Pearsons, T.N., Bosch, W.J., and 609 Fast, D.E. 2006. Comparison of life history traits between first-generation hatchery and wild 610 upper Yakima River spring Chinook salmon. T. Am. Fish. Soc. 135(4): 1130-1144.

611 Kormos, B., Palmer-Zwahlen, M., and Low, A. 2012. Recovery of coded-wire tags from Chinook 612 salmon in California's Central Valley escapement and ocean harvest in 2010. Technical report, 613 California Department of Fish and Game Fisheries Branch Administrative Report 2012-02.

614 Kostow, K.E., Marshall, A.R., and Phelps, S.R. 2003. Naturally spawning hatchery steelhead 615 contribute to smolt production but experience low reproductive success. T. Am. Fish. Soc. 616 132(4): 780-790.

617 Lasko, G.R., Titus, R.G., Ferreira, J.R., and Coleman, R.M. 2014. Straying of late-fall run Chinook 618 salmon from the Coleman National Fish Hatchery into the lower American River, California. 619 Calif. Fish Game, 100(4): 665-682. 
620 Mangel, M. 1994. Climate-change and salmonid life-history variation. Deep-Sea Research II, 41:

$62175-106$.

622 McHugh, P., Johnson, G. and Schaffler, J., 2015. Chinook FRAM Base Period Documentation:

623 Growth Functions. Report to Pacific Fishery Management Council. Available from

624 http://www.pcouncil.org/wp-

625 content/uploads/2015/10/D2_Att2_FRAM_Growth_Meth_Nov2015BB.pdf

626 Morita, K., Saito, T., Miyakoshi, Y., Fukuwaka, M.A., Nagasawa, T., and Kaeriyama, M. 2006. A

627 review of Pacific salmon hatchery programmes on Hokkaido Island, Japan. ICES J. Mar. Sci.

628 63(7): 1353-1363.

629 Naish, K.A., Taylor, J.E., Levin, P.S., Quinn, T.P., Winton, J.R., Huppert, D., and Hilborn, R. 2008.

630 An evaluation of the effects of conservation and fishery enhancement hatcheries on wild

631 populations of salmon. Adv. Mar. Biol. 53: 61-194.

632 Nickelson, T. 2003. The influence of hatchery coho salmon (Oncorhynchus kisutch) on the 633 productivity of wild coho salmon populations in Oregon coastal basins. Can. J. Fish. Aquat. Sci. 634 60(9): 1050-1056.

635 O'Farrell, M.R., Palmer-Zwahlen, M.L., and Simon, J. 2010. Is the September 1 river return date 636 approximation appropriate for Klamath River fall Chinook? NOAA Tech. Memo. NOAA-TM-

637 NMFS-SWFSC-468. 
638 O'Farrell, M.R., Satterthwaite, W.H., and Spence, B.C. 2012a. California Coastal Chinook salmon:

639 status, data, and feasibility of alternative fishery management strategies. NOAA Tech. Memo.

640 NMFS-SWFSC-494.

641 O'Farrell, M.R., Mohr, M.S., Grover, A.M., and Satterthwaite, W.H. 2012b. Sacramento River

642 winter Chinook cohort reconstruction: analysis of ocean fishery impacts. NOAA Tech. Memo.

643 NMFS-SWFSC-491.

644 Pacific Fishery Management Council. 2016. Pacific Coast salmon fishery management plan for

645 commercial and recreational salmon fisheries off the coasts of Washington, Oregon, and

646 California as revised through amendment 19. Pacific Fishery Management Council, 7700 NE

647 Ambassador Place, Suite 101, Portland, Oregon 97220-1384.

648 Palmer-Zwahlen, M., and Kormos, B. 2013. Recovery of coded-wire tags from Chinook salmon in

649 California's Central Valley escapement and ocean harvest in 2011. Technical report, California

650 Department of Fish and Game Fisheries Branch Administrative Report 2013-02.

651 Palmer-Zwahlen, M., and Kormos, B. 2015. Recovery of coded-wire tags from Chinook salmon in

652 California's Central Valley escapement and ocean harvest in 2012. Technical report, California

653 Department of Fish and Game Fisheries Branch Administrative Report 2015-04.

654 Pascual, M.A., Quinn, T.P., and Fuss, H. 1995. Factors affecting the homing of fall Chinook

655 salmon from Columbia River hatcheries. T. Am. Fish. Soc. 124(3): 308-320.

656 Quinn, T.P. 1993. A review of homing and straying of wild and hatchery-produced salmon. Fish.

657 Res. 18(1-2): 29-44. 
658 Quinn, T.P., and Fresh, K. 1984. Homing and straying in chinook salmon (Oncorhynchus

659 tshawytscha) from Cowlitz River Hatchery, Washington. Can. J. Fish. Aquat. Sci. 41(7): 1078-

6601082.

661 Reisenbichler, R.R., and Rubin, S.P. 1999. Genetic changes from artificial propagation of Pacific

662 salmon affect the productivity and viability of supplemented populations. ICES J. Mar. Sci. 56(4):

$663 \quad 459-466$.

664 Ruckelshaus, M.H., Levin, P., Johnson, J.B., and Kareiva, P.M. 2002. The Pacific salmon wars:

665 what science brings to the challenge of recovering species. Annu. Rev. Ecol. Syst. 33(Jan. 1):

666 665-706.

667 Satterthwaite, W.H., Mohr, M.S., O'Farrell, M.R., and Wells, B.K. 2012. A Bayesian hierarchical

668 model of size-at-age in ocean-harvested stocks - quantifying effects of climate and temporal

669 variability. Can. J. Fish. Aquat. Sci. 69(5): 942-954.

670 Satterthwaite, W.H., Mohr, M.S., O'Farrell, M.R., and Wells, B.K. 2013. A comparison of

671 temporal patterns in the ocean spatial distribution of California's Central Valley Chinook salmon

672 runs. Can. J. Fish. Aquat. Sci. 70(4): 574-584.

673 Satterthwaite, W.H., Carlson, S.M., Allen-Moran, S.D., Vincenzi, S., Bograd, S.J., and Wells, B.K.

674 2014a. Match-mismatch dynamics and the relationship between ocean-entry timing and

675 relative ocean recoveries of Central Valley fall run Chinook salmon. Mar. Ecol.-Prog. Ser. 511:

$676 \quad 237-248$. 
677 Satterthwaite, W. H., M. S. Mohr, M. R. O’Farrell, E. C. Anderson, M. A. Banks, S. J. Bates, M. R.

678 Bellinger, L. A. Borgerson, E. D. Crandall, J. C. Garza, B. J. Kormos, P. W. Lawson, and M. L.

679 Palmer-Zwahlen. 2014b. Use of genetic stock identification data for comparison of the ocean

680 spatial distribution, size at age, and fishery exposure of an untagged stock and its indicator:

681 California Coastal versus Klamath River Chinook salmon. T. Am. Fish. Soc. 143(1):117-133.

682 Seelbach, P., and Whelan, G. 1988. Identification and contribution of wild and hatchery

683 steelhead stocks in Lake Michigan tributaries. T. Am. Fish. Soc. 117(5): 444-51.

684 Solazzi, M.F., Nickelson, E., and Johnson, S.L. 1991. Survival, contribution, and return of

685 hatchery coho salmon (Oncsrhynchus kisutch) released into freshwater, estuarine, and marine

686 environments. Can. J. Fish. Aquat. Sci. 48(2): 2493-253.

687 Swain, D.P., Riddell, B.E., and Murray, C.B. 1991. Morphological differences between hatchery

688 and wild populations of coho salmon (Oncorhynchus kisutch): environmental versus genetic

689 origin. Can. J. Fish. Aquat. Sci. 48(9): 1783-1791.

690 Utter, F. 1998. Genetic problems of hatchery-reared progeny released into the wild, and how to

691 deal with them. B. Mar. Sci. 62(2): 623-640.

692 Vainikka, A., Kallio-Nyberg, I., Heino, M., and Koljonen, M.L. 2010. Divergent trends in life-

693 history traits between Atlantic salmon Salmo salar of wild and hatchery origin in the Baltic Sea.

694 J. Fish Biol. 76(3): 622-640.

695 Vøllestad, L.A., Peterson, J. and Quinn, T.P., 2004. Effects of freshwater and marine growth

696 rates on early maturity in male coho and Chinook salmon. T. Am. Fish. Soc. 133(3): 495-503. 
697 Vreeland, R.R., Wahle, R.J., and Arp, A.H. 1975. Homing behavior and contribution to Columbia 698 River fisheries of marked coho salmon released at two locations. Fish. Bull. 73: 717-725.

699 Waples, R.S. 1991. Genetic interactions between hatchery and wild salmonids: lessons from the 700 Pacific Northwest. Can. J. Fish. Aquat. Sci. 48(S1): 124-133.

701 Westley, P.A.H., Quinn, T.P., and Dittman, A.H. 2013. Rates of straying by hatchery-produced

702 Pacific salmon (Oncorhynchus spp.) and steelhead (Oncorhynchus mykiss) differ among species, 703 life history types, and populations. Can. J. Fish. Aquat. Sci. 70(5): 735-746.

704 Williams, J.G., 2006. Central Valley salmon: a perspective on Chinook and steelhead in the 705 Central Valley of California. San Francisco Estuary and Watershed Science, 4(3): Art. 2.

706 Williams, M.C. 2012. Spatial, temporal, and cohort-related patterns in the contribution of wild 707 Chinook salmon (Oncorhynchus tshawytscha) to total Chinook harvest in Lake Michigan Ph.D. 708 thesis, Michigan State University, East Lansing, Michigan. Available from 709 http://qfc.fw.msu.edu/Publications/Theses_Dissertations/2012/MWilliams_thesis.pdf.

710 Zaugg, W.S., Roley, D.D., Prentice, E.F., Gores, K.X., and Waknitz, F.W. 1983. Increased seawater 711 survival and contribution to the fishery of chinook salmon (Oncorhynchus tshawytscha) by 712 supplemental dietary salt. Aquaculture, 32(1): 183-188. 
Table 1. Variable definitions and symbols with baseline value(s) or range.

\begin{tabular}{|c|c|c|c|}
\hline Symbol & Variable & Definition or example & Baseline value(s) or range \\
\hline$A$ & Maximum age (subscript) & Oldest age of surviving individuals & 5 \\
\hline$a$ & Age (subscript) & Age class & $\{1,2,3,4,5\}^{a}$ \\
\hline$b_{a}$ & Maturation probability & Probability of spawning if alive at age $a$ & $\{0,0.03,0.5,0.9,1\}^{a}$ \\
\hline$C_{a}$ & Catch & Ocean harvest of age $a$ fish & $(\text { eq. } 2)^{b}$ \\
\hline CPS & Catch per stray spawner & Ratio $C_{T, h}: S_{T, h}$ & $(\text { eq. } 12)^{b}$ \\
\hline$e$ & Fishing intensity (effort) & Scalar applied to fishing vulnerability & $0.5(0.1,0.8)^{c}$ \\
\hline$f_{a}$ & Fishing mortality & Probability of ocean harvest if alive at age $a$ & $\left(f_{a}=e q_{a}\right)^{b}$ \\
\hline$h$ & Hatchery origin (subscript) & Captive-reared with hatchery life history effect & NA \\
\hline$G_{a}$ & Egg production & Eggs produced in natural areas at age $a$ & (eqs. 5,6$)^{b}$ \\
\hline$g_{a}$ & Fecundity & Female eggs per age $a$ spawner & $\{0,2100,2900,3000,3700\}^{a}$ \\
\hline$N_{a}$ & Cohort size & Number of individuals alive at age $a$ & $(\text { eq. } 1)^{b}$ \\
\hline$p_{a}$ & Survival & Age-specific survival probability (age $a$ to age $a+1$ ) & $\{0.01,0.5,0.8,0.8,0\}^{a}$ \\
\hline$p C$ & Proportion caught & Proportion of hatchery-origin fish caught in ocean harvest & (eq. 10) \\
\hline$p S$ & Proportion spawning & Proportion of hatchery-origin fish that spawn in natural areas & (eq. 11) $)^{b}$ \\
\hline pHOC & Ocean harvest composition & Proportion hatchery-origin among ocean catch & $(\text { eq. } 9)^{b}$ \\
\hline pHOG & Egg composition & Proportion hatchery-origin within natural-area egg production & $(\text { eq. } 8)^{b}$ \\
\hline pHOS & Spawner composition & Proportion hatchery-origin among natural-area spawners & $(\text { eq. } 7)^{b}$ \\
\hline$q_{a}$ & Fishing vulnerability & Probability of ocean harvest relative to "highest vulnerability" & $\{0,0.05,0.5,1,1\}^{a}$ \\
\hline$R_{a}$ & Returns & Number of age $a$ fish returning to spawn & $(\text { eq. } 3)^{b}$ \\
\hline$S_{a}$ & Spawners & Number of age $a$ fish spawning in natural areas & $(\text { eq. } 4)^{b}$ \\
\hline$T$ & Total (subscript) & Sum across ages $a=\{2,3,4,5\}$ & NA \\
\hline$w$ & "wild" (subscript) & Naturally-spawning fish with "wild" life history & NA \\
\hline$y$ & Stray rate & Probability of straying to spawn in natural area & $0.3(0,1)^{c}$ \\
\hline$\phi_{b}$ & Maturation ratio & $b_{a, h}: b_{a, w}=\min \left\{\left(\phi_{b} b_{a, w}\right), 1\right\}: b_{a, w}$ & $1(0.1,8)^{c}$ \\
\hline$\phi_{g}$ & Fecundity ratio & $g_{a, h}: g_{a, w}=\phi_{g} g_{a, w}: g_{a, w}$ & $1(0.1,8)^{c}$ \\
\hline$\phi_{N}$ & Cohort ratio & $N_{1, h}: N_{1, w}=\phi_{N} N_{1, w}: N_{1, w}$ & $1(0.1,8)^{c}$ \\
\hline Note: & \multicolumn{3}{|l|}{ NA indicates a non-numeric entry. } \\
\hline & \multicolumn{3}{|c|}{ Age schedule of vital rates for ages $a=\{1,2,3,4,5\}$ (e.g., $b_{a}=\{0,0.03,0.5,0.9,1\}$ ). } \\
\hline$b$ & \multicolumn{3}{|c|}{ Equation determining endogenous (output) variable } \\
\hline & 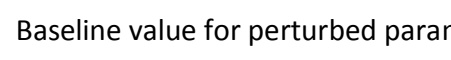 & g with (min, max) of & \\
\hline
\end{tabular}




\section{$713 \quad$ Figure Legends}

714 Fig. 1. Population model schematic. Lines denote transitions between stages, labeled with rates as defined in Table 1. $N=$ number, $a=$ age, $b=$ maturation rate, $p=$ survival, $f=$ fishing mortality, $y=$ stray rate, $h=$ hatchery-origin, $w=$ natural-origin. Egg production not shown.

Fig. 2. Different lines predict individual rate effects on the proportion hatchery-origin among spawners ( $p H O S)$, the proportion hatchery-origin among ocean fishery catch $(p H O C)$, the proportion of hatchery fish ending up in ocean catch $(p C)$ and the proportion of hatchery fish that end up spawning in natural areas $(p S)$. Panels show the effects of varying one the following

722 rates $\left(\phi_{N}, \phi_{b}, e, y\right)$ when the other four are held constant at baseline values $\left(\phi_{N}=1, \phi_{b}=1, e=\right.$ rates $(y)$ of hatchery fish.

Fig. 3. Contours predict the proportion of natural-area spawners that are of hatchery origin

727 (pHOS) under different pairwise combinations of varying cohort ratios $\left(\phi_{N}\right)$, maturation ratios

$728\left(\phi_{b}\right)$, fishing intensity $(e)$ and stray rates $(y)$, with the other two of these four parameters held at 729 baseline rates $\left(\phi_{N}=1, \phi_{b}=1, e=0.5, y=0.3\right)$.

Fig. 4. Contours predict the proportions of natural-area egg production made by hatchery-origin fish $(p H O G)$ under different pairwise combinations of varying cohort ratios $\left(\phi_{N}\right)$, maturation 
733 ratios $\left(\phi_{b}\right)$, fecundity ratios $\left(\phi_{g}\right)$, fishing intensity $(e)$ and stray rates $(y)$, with the other two of

734 these four parameters held at baseline rates $\left(\phi_{N}=1, \phi_{b}=1, \phi_{g}=1, e=0.5, y=0.3\right)$. Note that 735 pairwise combinations without changes along both axes have been omitted.

737 Fig. 5. Top row $(a-c)$ predicts the proportion of ocean harvest that would be of hatchery-origin $738(p H O C)$ under different different pairwise combinations of varying cohort ratios $\left(\phi_{N}\right)$, 739 maturation ratios $\left(\phi_{b}\right)$, fishing intensity $(e)$ and stray rates $(y)$, with the other two of these four 740 parameters held at baseline rates $\left(\phi_{N}=1, \phi_{b}=1, e=0.5, y=0.3\right)$. Bottom row $(d-f)$ predicts 741 Catch-per-Stray spawner ratios (CPS contours on a natural logarithmic scale) under different 742 parameter combinations (again with all but two fixed at baseline rates). Note that no panels are 743 required to show effects of stray rates $(y)$ on $p H O C$ because straying occurs after fish have left 744 the ocean and there is no effect of $\phi_{N}$ on CPS because hatchery cohort scaling applies equally to 745 catch $(C)$ and spawner cohorts $(S)$. 


\section{Natural production $\quad$ Hatchery production}

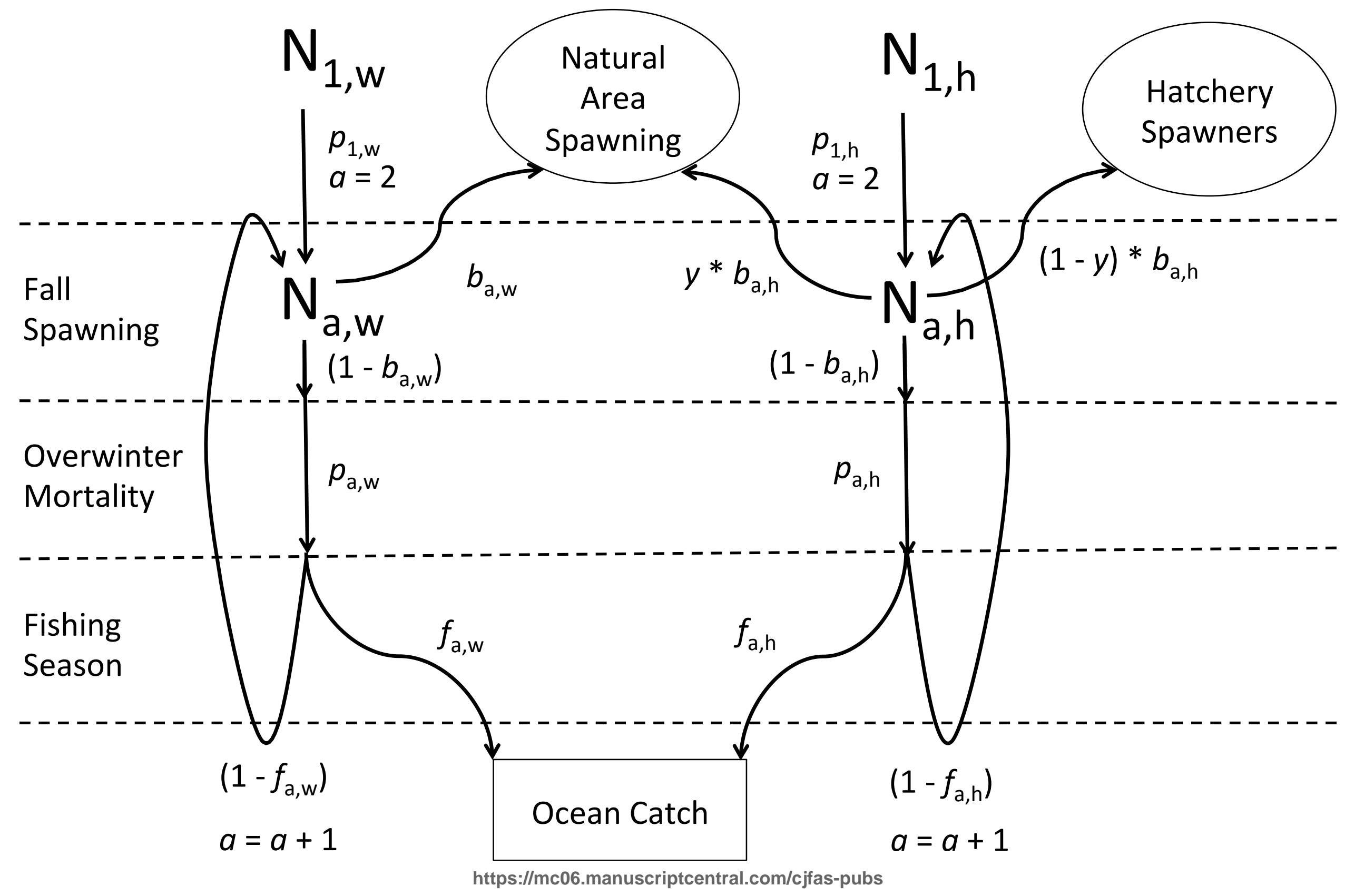


(a)

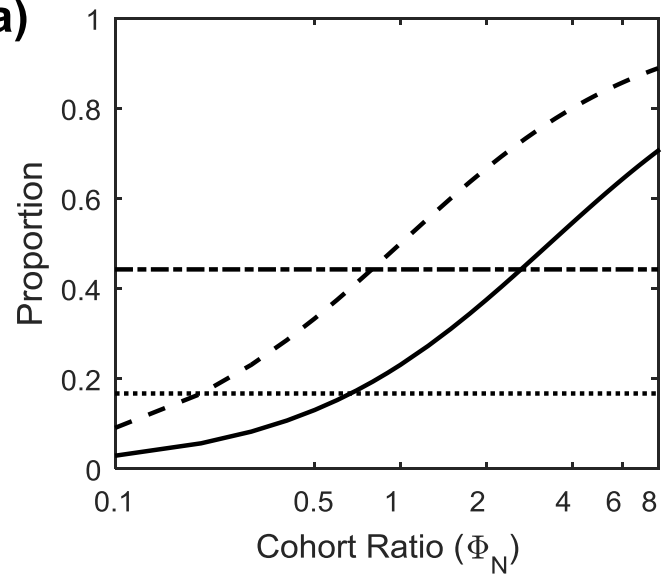

Fishing Intensity

(c)

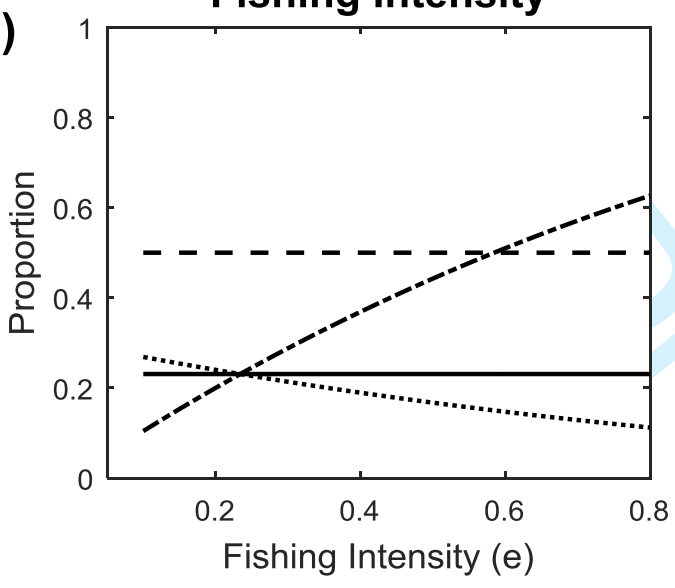

(b)

Maturation Ratio
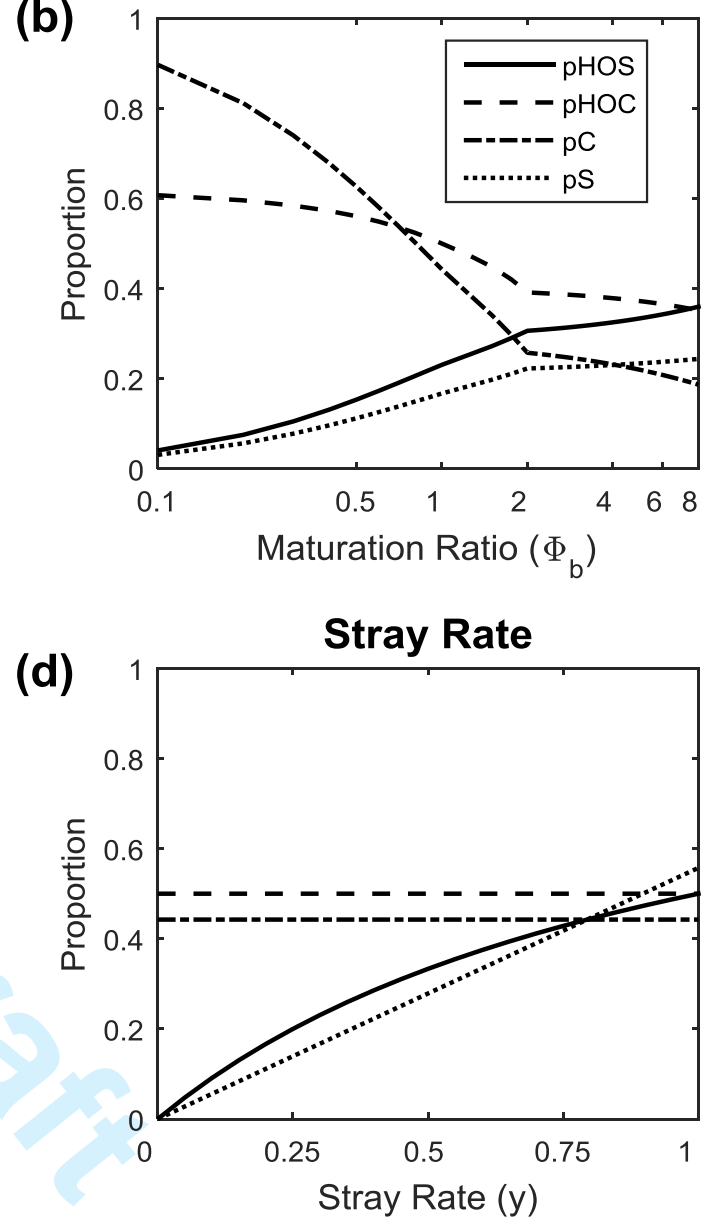
(a)

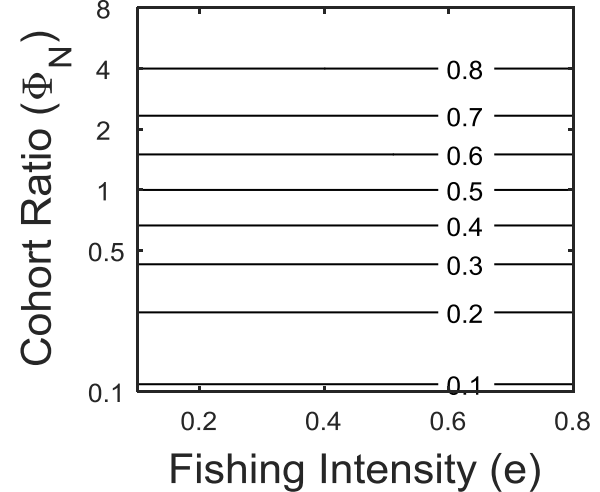

(d)

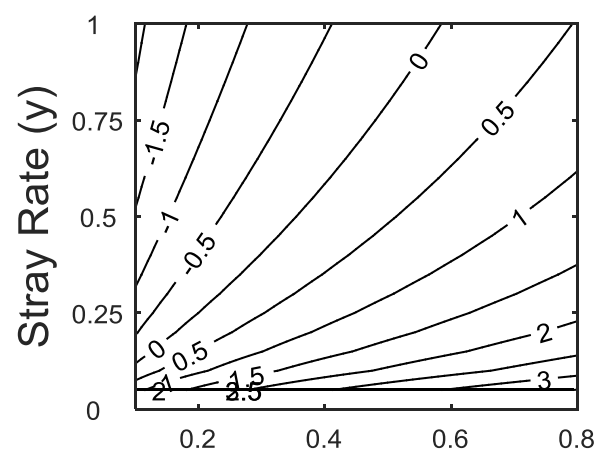

Fishing Intensity (e) (b)

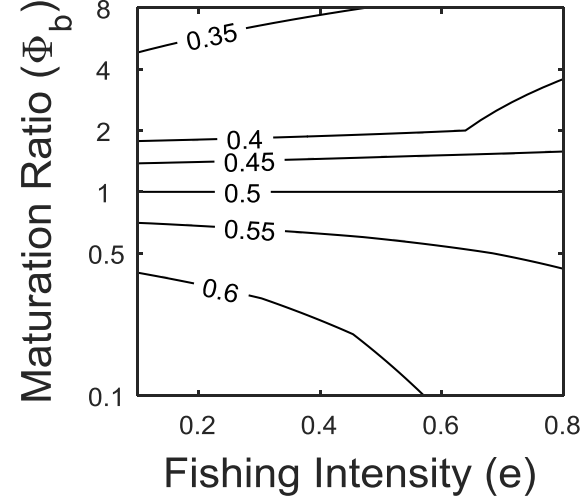

(e)

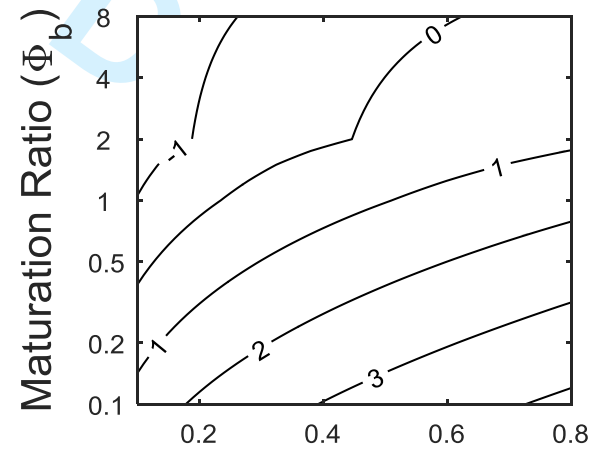

Fishing Intensity (e) (c)

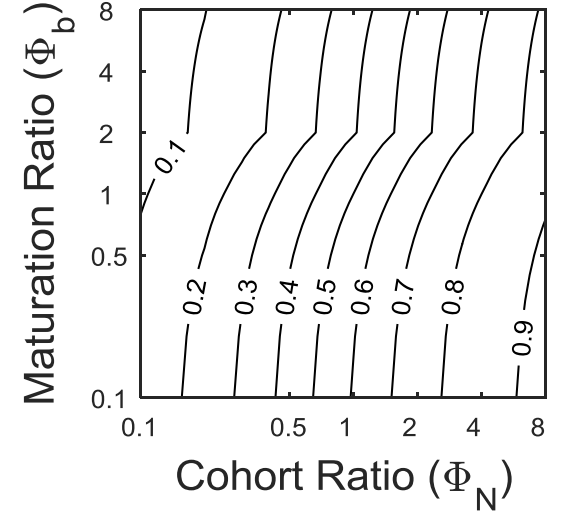

(f)

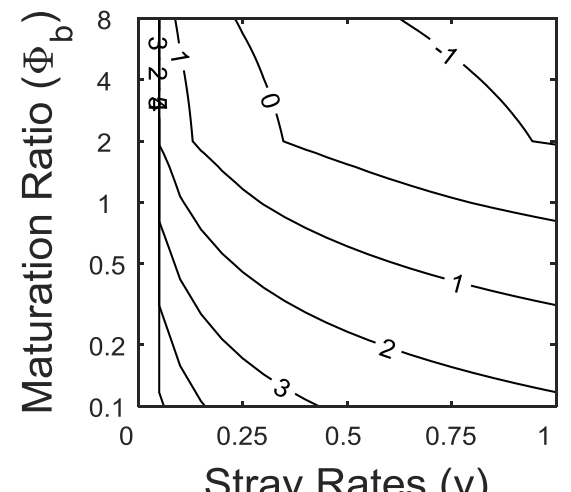




\section{Supplementary materials}

In the main text, we present sensitivity analyses to parameter values and multipliers individually and in pairwise combinations, but assume the same effects age on fecundity and fishery vulnerability throughout. In this supplement, we explore the consequences of relaxing this assumption for the effects of stray rate and maturation ratios on catch per stray spawner $(C P S)$ or catch per stray egg $(C P G)$. We focus on these metrics because they are independent of the overall scale of hatchery versus natural production, and focus on maturation and stray rates because we are most interested in the capacity for altered stray rates or maturation schedules to alter the tradeoff between hatchery contributions to harvest versus natural area spawning and egg production.

Fig. S1 shows the consequences of relaxing the assumption that fecundity increases with age. Since fecundity only affects egg number, we present the effects of stray rate and maturation ratios on $C P G$ under different fecundity scenarios. In the baseline scenario, age specific fecundities $\left\{g_{2}, g_{3}, g_{4}, g_{5}\right\}=\{2100,2900,3000$, $3700\}$, in the "flat" scenario $g_{2-5}=3000$, and in the "reversed" scenario $\left\{g_{2}, g_{3}, g_{4}, g_{5}\right\}$ $=\{3700,3000,2900,2100\}$. Results are highly similar both qualitatively and quantitatively across this range of scenarios (Fig. S1a-S1c, note that close inspection reveals that the plots are not identical). To confirm that our model was capable of responding to extreme changes in the typical fecundity schedule, we verified that making the youngest fish much more fecund than older fish (biologically implausible, $g_{2}=3000$ and $g_{3-5}=100$ ) yielded a detectable change in the contour plot, although the qualitative effects of increased stray rate or maturation rate are preserved (Fig. S1d).

Fig. S2 shows the consequences of replacing the default "selectivity" on different age classes by the fishery $\left(\left\{q_{2}, q_{3}, q_{4}, q_{5}\right\}=\{0.05,0.5,1,1\}\right.$, Fig. S2a) with weaker selectivity (making younger fish more vulnerable, and thus increasing overall exploitation for a given fishery intensity, $\left\{q_{2}, q_{3}, q_{4}, q_{5}\right\}=\{0.25,0.75,1,1\}$, Fig. S2b) or a non-selective fishery (thus increasing total exploitation even further, $q_{2-5}=1$, Fig. S2c). Finally, we explore an implausible decrease in vulnerability with 
age $\left(\left\{q_{2}, q_{3}, q_{4}, q_{5}\right\}=\{1,0.75,0.5,0.25)\right.$ in Fig. S2d. The qualitative pattern is the same in all cases, with CPS reduced by earlier maturation or higher stray rates. Overall catch per stray goes up as selectivity is reduced (young fish are more vulnerable) because total catch is higher and fewer fish survive to spawn.

\section{a) Baseline}

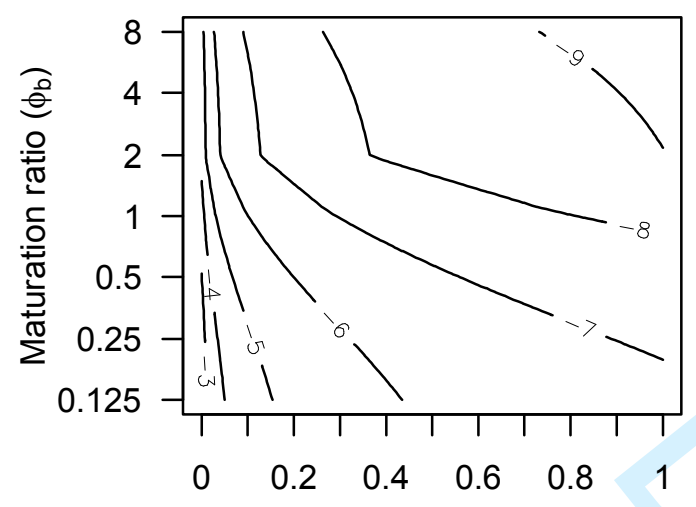

Stray rate $(y)$

c) Reversed

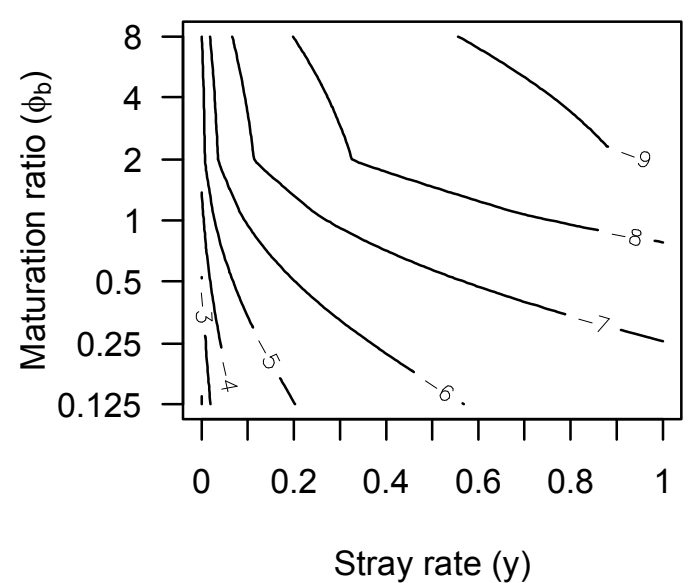

b) Flat

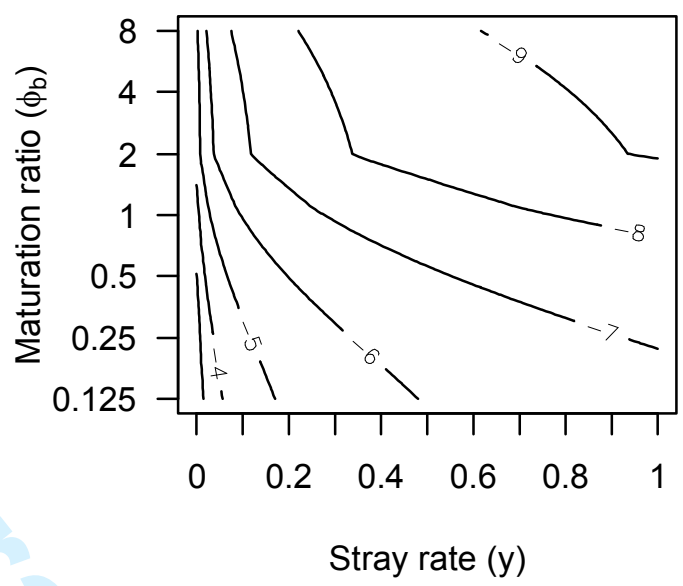

d) Extreme Reversal

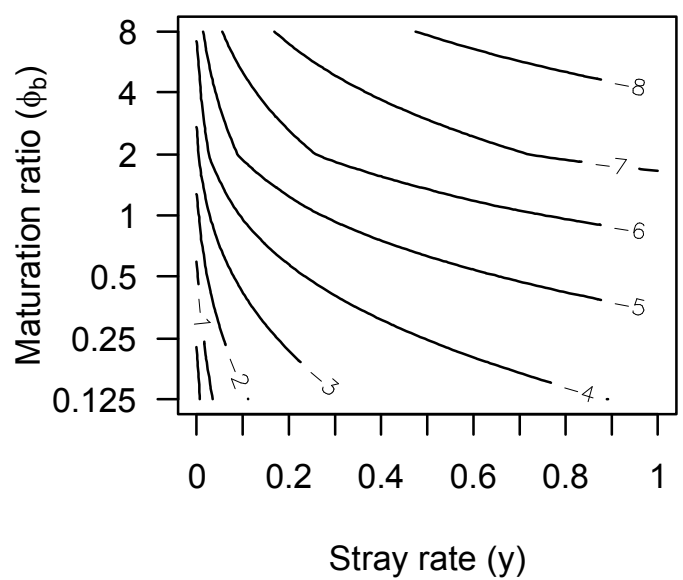

Fig. S1. Natural log of catch per stray egg $(C P G)$ as a function of maturation ratio and stray rate under the baseline scenario for fecundity increasing with age (a), no effect of age on fecundity (b), a decline of fecundity with age (c), or an extreme decline of fecundity with age (d). 
a) Baseline selectivity

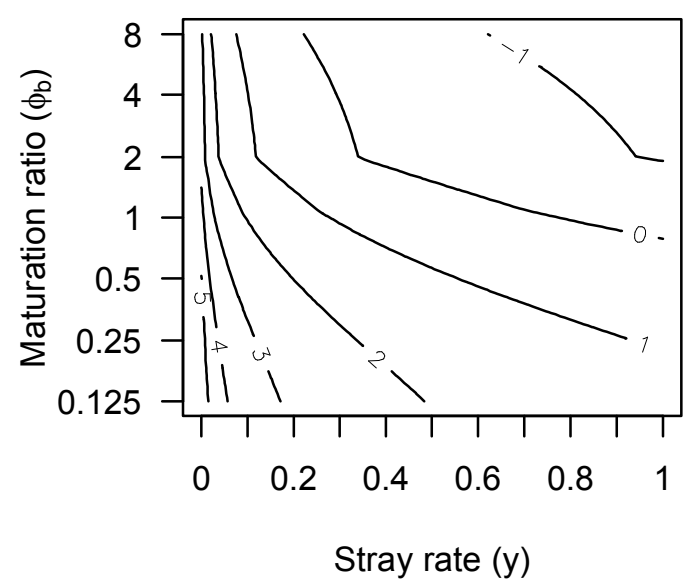

c) No selectivity

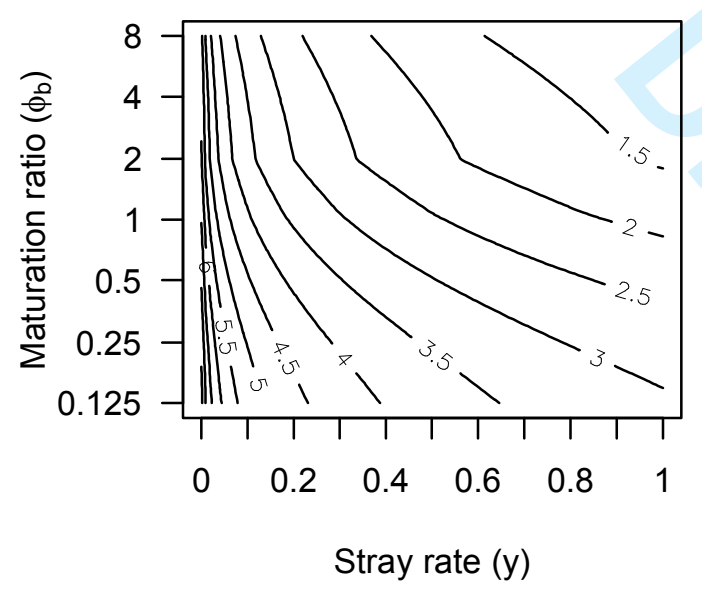

b) Weak selectivity

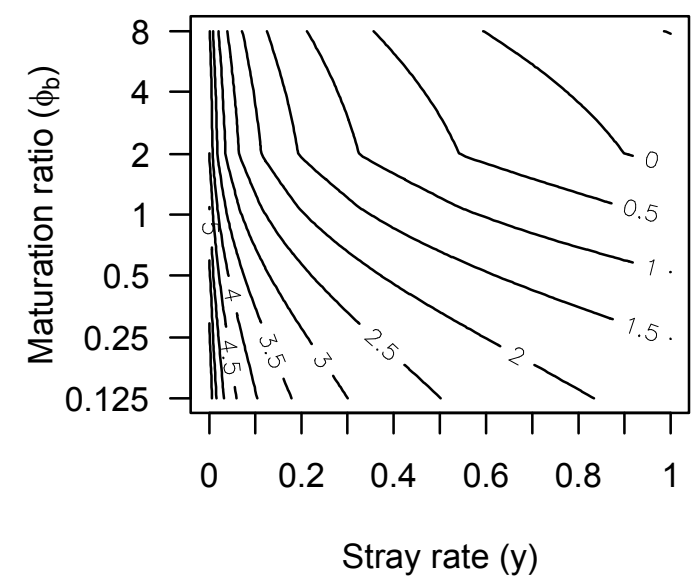

d) Reverse selectivity

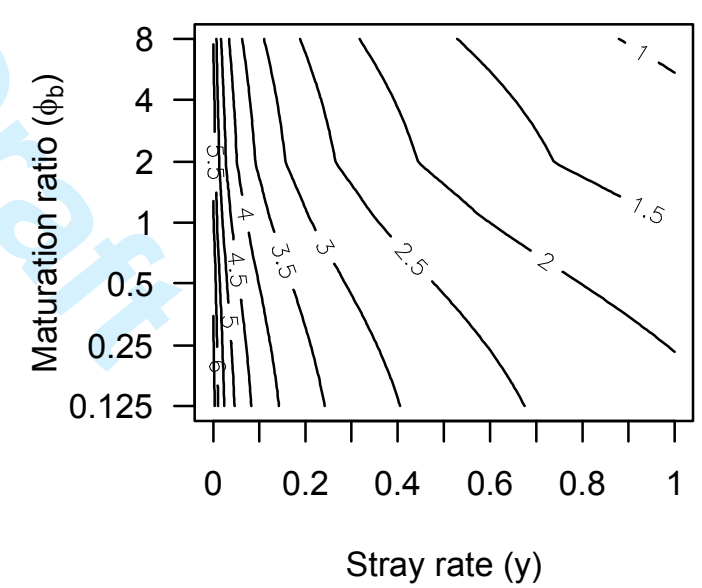

Fig. S2. Natural log of catch per stray spawner $(C P S)$ as a function of maturation ratio and stray rate under the baseline scenario for fishing vulnerability increasing with age (a), a less selective fishery in which old fish are still most vulnerable (b), a nonselective fishery (c), or a decline of fishery vulnerability with age (d). 